\title{
Approaching the Internalization Challenge of Grid Technologies into e-Society by e-Human "Grid" Ecology
}

\author{
Tobias A. Knoch ${ }^{1,3 *}$, Volkmar Baumgärtner ${ }^{4}$, \\ Frank G. Grosveld ${ }^{2}$, and Kurt Egger ${ }^{5}$
}

${ }^{1}$ Biophysical Genomics \& Erasmus Computing Grid, ${ }^{2}$ Dept. Cell Biology \& Genetics, Erasmus MC, Dr. Molewaterplein 50,3015 GE Rotterdam, The Netherlands.

${ }^{3}$ Biophysical Genomics, Genome Organization \& Function, BioQuant Centre/

German Cancer Research Center, Im Neuenheimer Feld 267, 69120 Heidelberg, Germany.

${ }^{4}$ Regionalverband Mittlerer Oberrhein, Baumeisterstr. 2, 76137 Karlsruhe, Germany.

${ }^{5}$ Emeritus Institute for Plant Sciences, University of Heidelberg,

Pleikartsförsterhof 2, 69124 Heidelberg, Germany.

TA.Knoch@taknoch.org, Volkmar.Baumgaertner@region-karlsruhe.de,

F.Grosveld@erasmusmc.nl, KEgger@hip.uni-heidelberg.de

\begin{abstract}
The amount of information is growing exponentially with ever-new technologies emerging and is believed to be always at the limit. In contrast, huge resources are obviously available, which are underused in the IT sector, similar as e.g. in the renewable energy sector. This is especially for grid with its fast turnover rates very astonishing considering the barriers for further development put forward by the inability to satisfy the need for such resources. The phenomenon is a typical example of the Inverse Tragedy of the Commons, i.e. resources are underexploited in contrast to the unsustainable and destructing overexploitation in the Classic Tragedy of the Commons. An analysis of IT and the grid sector which attempts to share resources for better usage efficiency, reveals two challenges, which lead to the heart of the paradox: i) From a macro perspective all grid infrastructures involve not only mere technical solutions but also dominantly all of the autopoietic social sub-systems ranging from religion to policy. ii) On the micro level the individual players and their psychology and risk behaviour are of major importance for acting within the macro autopoietic framework. Consequently, the challenges of grid implementation are similar to those of other pressing global issues as e.g. climate protection. This is well described by extending the Human Ecology triangle to a rectangle: invironmentindividual-society-environment. By applying this extension of this classical field of interdisciplinary basic and applied research to the grid sector, i.e. by further extension to an e-Human Grid Ecology rational, the Grid Inverse Tragedy of the Commons can be understood and approached regarding the internalization challenge into e-Society and e-Life, from which then guidelines for the day-to-day management can be derived. This is of general importance for many complex fields and thus with similar paradoxes and challenges.
\end{abstract}

Keywords. Grid infrastructures, inverse tragedy of the commons, autopoietic sub-systems, risk deep psychology, e-society, e-human grid ecology.

*Corresponding Author: TA.Knoch@taknoch.org 


\section{Introduction}

With ever-new technologies emerging from $\mathrm{R} \& \mathrm{D}$ also the information amount to be stored and processed is exponentially growing and thus believed to be always at the limit. IT has become the key to success in modern life: R\&D is meanwhile mostly based on the storage and analysis of huge data amounts, whether for elementary particle physics or the industrial in silicio design of cars, aircrafts or entire production facilities. In health care, diagnosis and treatment rely on imaging facilities, their sophisticated analysis and treatment planning. In logistics, the shipment of goods, water, electricity and fuels is driven by efficient distribution management systems. Beyond, the financial and risk management sectors are unthinkable without modeling. Finally, the IT sector itself is inevitably carried by the creation and manipulation of data streams. Thus, currently, the demands outweigh the useable resources by far and especially the public sector struggles to increase the accessible IT resources.

Limits showing e.g. syntropic/entropic materialistic, energetic or other barriers as those of the IT sector, are well known [1,2]. Such limits have constrained life since its beginning and are one of the evolutionary drivers by the "survival of the fittest". Exponential demand growth until reaching a limit seems to be an inherent property of life and evolution in general [3]. The other side of demand growth - waste and pollution - complies with this similarly, although it is not using a resource but destroying the purity of another one. Obviously, this sustainability challenge beyond the materialistic regime can be found on all evolutionary levels up to the psychological, societal and cultural level. All these levels act as a possible cause for exponential growth.

Especially, the abilities of man in his modern societies have accelerated the use of common resources tremendously reaching the planetary carrying capacity [4]. Climate change and the sustainability challenge, thus is a complex combination of various effects, which in their holistic consequences have reached an unsustainable level threatening survival. The (Classic) Tragedy of the Commons [5-10] describes this dilemma, in which (multiple) independently acting individuals due to their own selfinterest can ultimately destroy a shared limited resource even though it is clear that it is not in the long-term interest of the community locally or for the society in general.

On universal time scales syntropy/entropy laws obviously predict that mankind will reach fundamental limits [3]. Nevertheless, on short time scales huge resources are available for development: Due to the pervasiveness of PCs, their number has grown $>1$ billion world-wide, outweighing that of specialized computing centers by a factor $>100$. Since the capacity is peak performance oriented, less than $5 \%$ are used, i.e. more than $95 \%$ of the capacity would be available $99 \%$ of the time. These resources have been already paid for including their external follow-up costs (environmental etc.). The same holds to less extent for cluster infrastructures due to virtualization strategies. E.g. the Erasmus Computing Grid [11] with $\sim 15,000$ PC $(\sim 30,000$ cores, $\sim 30$ Tflops), i.e. a $\sim 22 \mathrm{M} €$ investment. Thus, in the notoriously under-funded public domain more efficient resource usage by means of grid is of major importance.

In many sectors better resource management can increase the efficiency tremendously. Thus, at least locally the disaster of reaching the (physical) limit can be delayed. A prime example from the production of fundamental raw materials is e.g. the integrated production in the chemical industry [12]: Here byproduct usage, i.e. the 
waste of one process, is reused in another one often even as main process component [13]. Integrated production can reach the level of an extremely fine-tuned ecological organism (as in the highly sophisticated chlorine chemistry) that little changes have severe "survival" consequences for the whole system $[14,15]$. In real biological systems, however, there is more flexibility for such changes as in the highly integrated and sophisticated agro-forestry systems e.g. in Indonesia, which have been developed over centuries reaching extremely high efficiencies and are one of the biggest cultural achievements ever [15]. In both cases the efficiency, i.e. the relation between system input and output, are maximized and beat every other process or management [16].

Here, we analyze the internalization challenge of grid technologies [17] into $e$ Society by what we call e-Human Grid Ecology, describing adequately the integrated holistic ecology like system parameters and strategies necessary. Therefore, we introduce the novel notion of the Inverse Tragedy of the Commons, i.e. that the resources are underused in contrast to their overexploitation. This phenomenon is generic and also found e.g. in the climate issue and is derived from an analysis and combination of the grid sector and the challenges emerging on the micro level of the individual with its security/risk psychology [18] as well as on the macro level of autopoietic social sub-systems [19-21]. To derive points of action, we will extent the classical Human Ecology framework [22, 23] to describe the interactions between invironmentindividual-society-environment completely. This will then lead to e-Human Grid Ecology, a rational allowing to understand and approach the Inverse Tragedy of the Commons of grids and other fields with similar paradoxes as those in (e-)Society.

\section{The Generic Organization of Grid Infrastructures}

Since obviously huge resources are available in IT alike the renewable energy sector, despite constant shortage claims, this paradoxical phenomenon can be approached by analysing grid infrastructures and their organization: The Erasmus Computing Grid (ECG) [11] exploits $\sim 15,000$ PC ( 30,000 cores, $~ 30$ Tflops) donated by the Erasmus Medical Center and the Hogeschool Rotterdam via the middleware CONDOR, a new management system and a central entry port - the ECG Office. It is one of the largest desktop grids for the biomedical research, education and care sectors. MediGRID [24-26] with its services branch Services@MediGRID operate the biomedical research and care grid of the national German D-Grid. The mainly cluster resources are donated and maintained by local universities and connected by different middlewares with local and central access points/portals using high-security protocols under medical conditions. MediGRID is one of the most advanced HealthGrids combining storage, computing and visualizations in the biomedical sectors [24-26].

Obviously, four levels of organization are involved (Fig. 1) i) users, ii) organizing broker organizations, iii) donor organizations, and iv) individual donors. More abstract this means i) individuals and ii) associations to different degree on each of these four levels. Consequently, there is a micro level from which a macro level emerges, having again an influence on the micro level. The micro level is constituted by an invironment and the macro level creates an environment, which already constitutes the Human Ecology rectangle to which we come back later again (6.). 


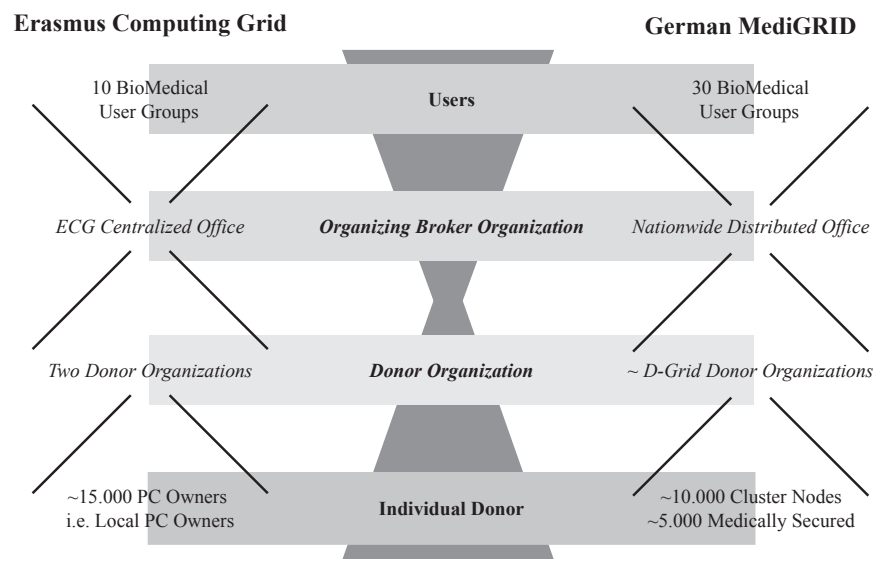

Fig. 1. Abstraction and detailed structure of the Erasmus Computing Grid [11] and the German MediGRID [24-26] showing the four levels involved in grid infrastructures: i) users, ii) organizing broker organizations, iii) donor organizations, and iv) individual donors. Although, the details may vary the structure leads to similar changes on the micro and macro level, which can be understood by the Human Ecology rectangle (6.).

\section{The Inverse Tragedy of the Commons in Grid Infrastructures}

Thus, obviously there are affluent resources and also solutions for their efficient exploitation. Nevertheless, sharing them completely, e.g. by integrated holistic ecology like systems, seems hard since grid infrastructures slowly emerge, which is paradoxical, since IT has great technical opportunities with fast turnover rates.

The analysis of grid organizations showed already that there is a micro level from which a macro level emerges. In the case of over-exploitation of common resources as e.g. in the climate change dilemma, the exactly same complex interplay between the individual and the society as well as the invironment and the environment appears. Here, this is well known as the so called Classic Tragedy of the Commons [5-10], in which (multiple) independently acting individuals due to their own self-interest can ultimately destroy a shared limited resource even though it is clear that it is not in the long term interest of the local community and society as a whole. In the case of under exploited resources there seems to be the same phenomenology of the challenge put forward. This until now not theoretically defined phenomenon we - as a logical consequence - name the Inverse Tragedy of the Commons and define as (Fig. 2):

The (Classic) Tragedy of the Commons:

A resource belonging to all and being on limited demand is

OVEREXPLOITED by the user due to responsibility diffusion!

$$
<=>\text { TRANSFORMATION }<=>
$$

:The INVERSE Tragedy of the Commons A resource belonging to all and being in affluent availability on limited demand is UNDEREXPLOITED by potential users due to responsibility diffusion! 
Interestingly, not only is responsibility diffusion the most likely and general reason for the appearance of both tragedies, but also the psychological description for both the micro and the macro level hits the same archetypical traits (Fig. 2). The underused potentials and over-used resources clearly show how from a virgin resource opportunity, concrete objects emerge with their attached limitation burden (Fig. 2). Thus, the complex field created, describes exactly the tension found in resource limitation phenomena and evolutionary emergence.

Pinpointing the phenomenon of under exploited potentials to the same phenomenological root as the well known phenomenon of over exploited resources opens now the complete opportunities and tool set to examine the challenge of introducing grid as well as its principle day-to-day management.

\section{The Grid Tragedy of Autopoietic Social Sub-Systems}

The challenge of integrating resources in a virtualized manner involves naturally all stakeholders of society (Fig. 1). The existence of a grid Inverse Tragedy of the Commons and its macro social aspects, point to the major importance of the interaction complexity of the social sub-systems theory by Niklas Luhmann [20, 21]. It is based on the autopoietic concept of Humberto Maturana and Francisco Varela [19] - the most advanced social systems theory, describing the huge complexity of the macro sociality of the grid phenomenon. An autopoietic system is a network of processes consisting of: i) interactions and transformations continuously regenerating and realizing its networks of existence, and ii) the constitution of the system as a unity in space in which the component exist by specifying the topological domain of its realization. Central to this description of evolutionary emergence, i.e. self-reproducing systems, is the material and information exchange between the components. Social systems are obviously communication systems, with society being the most encompassing one. Consequently, many of the conundrums appearing during the society internalization become evident and are in agreement with the Inverse Tragedy of the Grid Commons:

In detail around seven social sub-systems can be defined and reflect the evolutionary emergence from deep psychology to society [21]: i) religion, ii) education, iii) science, iv) art, v) economy, vi) jurisdiction, vii) policy. All of these systems have their internal code of communication and their own connectivity interface to the other sub-systems. This results in hug barriers: e.g. the religious code of believe or notbelieve is incompatible with the have or not have money code of the economic sector. This is even more true for science (true vs. non-true), jurisdiction (just vs. un-just) and politics (power vs. no-power), which have nothing to do with education (knowledge vs. no-knowledge). Since grid infrastructures belong currently mostly to the academic sector [11, 24-26], their widespread usage within society, i.e. their internalization into society, is deaccelerated by the lack of interoperability between these sub-systems. Consequently, the Inverse Tragedy of the Commons results in

\section{The Tragedy of Autopoietic Social Sub-Systems:}

Sub-systems have their own code of communication and are separated from each other in a way blocking in principle a consistent integration although they form a society with all their contradictions this leads to blockage of the system. 


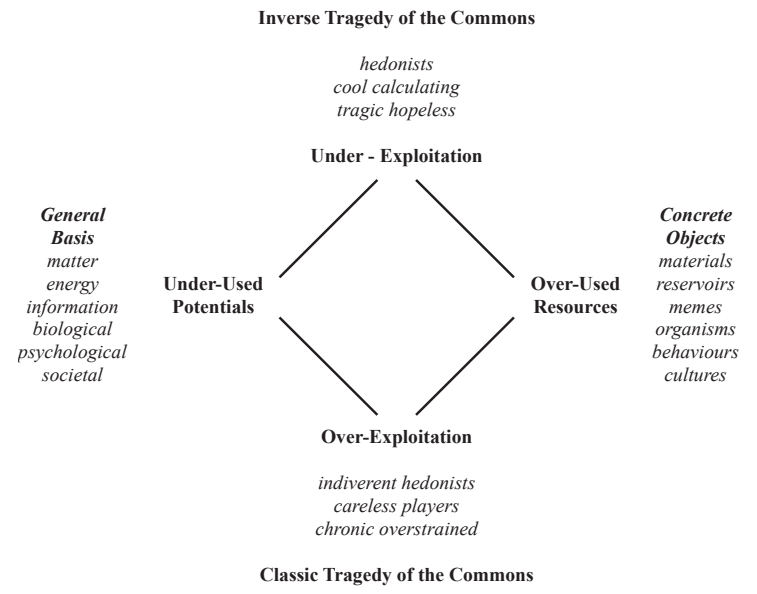

Fig. 2. Generalization of the Inverse Tragedy of the Commons: the Classic and Inverse Tragedy of the Commons are directly complementary to each other and can on the deep psychology level associated with complementary pears of archetypical behavioural traits. This is in line with the complementary under-used potentials and over-used resources, which emerge from the potentials by freezing of potentials into concrete objects with corresponding limits.

This macro level tragedy clarifies that grid organizations are just another example for complex infrastructures whose efficiency increase depends beyond more or less complex technical solutions on the participation of all sub-systems concerning their societal internalization. This analysis and its acceptance is an important knowledge opening huge opportunities to examine and approach the challenge of introducing grids and their management. Beyond, this analysis makes the challenges in other sectors, which might reside in other sub-systems, obvious as well. Consequently, the Classic and Inverse Tragedy of the Commons can be understood as a societal challenge with the opportunity to be resolved.

\section{The Grid Tragedy of Security/Risk/Profit Psychology}

Since the macro level of social sub-systems emerges evolutionarily from the micro level [18], one needs to consider the individual for whom each implementation and internalization of a new technology is based on a positive relation between the risk and the profit involved. Thus, the level of altruism leading to successful sharing on the individual level and its commitment beyond its own job/agenda, as well as that of its own institution without incentive structure to take responsibilities, also leads to responsibility diffusion. Even the clear win-win situations for individual grid users are under these circumstances hard to communicate and even the additional networking effects result hardly in the set-up or usage of grids. It is also unlikely that people take the risk to exceed their own budget and corresponding responsibilities, when future results and its benefits are unclear to them. As long as sharing is voluntary and in 
hand with uncertainty and risks, it is less likely that individual problem owners will behave altruistically on behalf the societal benefit. Consequently, on the micro level the situation is that of a perverse Inverse Tragedy of the Commons: the commons is not abused or overexploited, but in contrast the tremendous resources are not used at all despite the needs and obvious benefits, due to secondary irrational interests.

Thus, the integration challenge involves the individual of the different institutionalized society stakeholders. These individuals shape the individual actions according to their function in a social sub-system. How an individual perceives the security/risk/profit ratio depends on its personal security/risk/profit psychology matrix:

\section{Deep Psychology Security/Risk/Profit Cascade:}

emotional individual s/r/p perception

rational $\mathrm{s} / \mathrm{r} / \mathrm{p}$ knowledge acceptance

internalized incidental $\mathrm{s} / \mathrm{r} / \mathrm{p}$ behaviour

accepted legal and political s/r/p scenarios

lived religious and cultural s/r/p archetypi
:Autopoietic Sub-System Correspondence

genetics and deep psychology

education and science

economics

jurisdiction and politics

religion, art and culture

Thus, this matrix describes a similar challenge on the micro level similar to the macro level with conflicting personal positions and internal balancing the invironment with the environment. This creates on the micro level again a tragedy:

\section{The Tragedy of Security/Risk/Profit Psychology:}

Individuals balance constantly a complex combination of invironmental and environmental security/risk/profit deep psychology factors whose contradictions lead to responsibility diffusion.

Unfortunately, the identification and analysis of this tragedy is by far more challenging concerning management guidelines, due to the hardly changeable basis (e.g. the genetic basis) and the time scales involved, in contrast to the macro level, where bypassing measures and changes can in principle be implemented at will. Consequently, this tragedy has to be tackled with big care and shows that the Inverse Tragedy of the Commons can really be addressed by a Human Ecology rectangle approach (6.).

\section{6 e-Human Grid Ecology}

To overcome the "dare-to-share" attitude in respect to the Inverse Tragedy of the Commons and its base tragedies in the grid sector, a sustainable grid approach in an ecology-like manner combining the micro and macro level is crucial. Since these are similar phenomena as e.g. in climate protection, the interdisciplinary applied field of Human Ecology [15, 18, 22, 23] gives a framework for their combination, followed by understanding and approaching direct guidelines of the management of grids. $\mathrm{Hu}$ man Ecology was developed originally by Robert Park (1864-1944) and Ernest Burgess (1886-1966) and evolved in Chicago in the 1920's in close connection to the field of city development. Human Ecology classically deals with the complex interplay between i) the individual, ii) the society, and iii) the environment, which usually is il- 


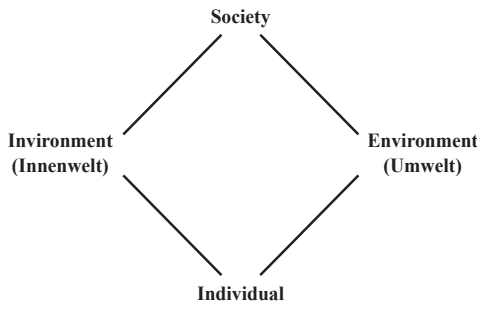

Fig. 3. The Human Ecology rectangle describes the relation between the invironment (Innenwelt), the individual, the society and the environment (Umwelt). It is the extension of the incomplete classical Human Ecology triangle, which consists only of the individual, the society and the environment but not the invironment. The invironment and the environment as well as the individual and the society are complementary pairs spanning a field between them. The invironment thereby constitutes the Innenwelt; the individual forms society; to the individual society gets a general environment as the invironment constitutes much of the society.

lustrated by the so called Human Ecology triangle. This framework is used to investigate many a complex mankind related challenges as e.g. the exponential demand growth until reaching a limit, its inherent property of life and evolution, as well as waste and pollution related issues. Obviously, these sustainability questions beyond the materialistic world are found on all evolutionary levels up to the psychological, societal and cultural one and involve also every cause for exponential growth.

The detailed analysis of the Inverse Tragedy of the Commons by investigating the Tragedy of Autopoietic Social Sub-Systems and the Tragedy of S/R/P Psychology, proposes the extension of the classical Human Ecology triangle to a rectangle consisting of: i) invironment ii) individual, iii) society, and iv) environment (Fig. 3). It describes the relation between the invironment (Innenwelt), the individual, the society and the environment (Umwelt). The invironment and the environment as well as the individual and the society are complementary pairs and create a field. The invironment thereby constitutes the Innenwelt, the individual forms society, the individual society creates an environment as the invironment constitutes much of the society. The rectangle reflects the mirco level (invironment and individual) and the macro level (society and environment) correctly. This fits the field of the Classic and Inverse Tragedy of the Commons, with its under-used potentials and over-used resources.

Consequently, the classic Human Ecology paradigms to understand the Classic and Inverse Tragedy of the Commons can now be used to define the corresponding subfield for $e$-Live and $e$-Society with e-Invironment and e-Environment extending the classic notion of ecology and using it in its detailed consequences for the understanding and management to internalize grids into society to increase dramatically the efficiency of resource exploitation dramatically to its e-ecology sustainable limits.

\section{The Definition of e-Human "Grid" Ecology}

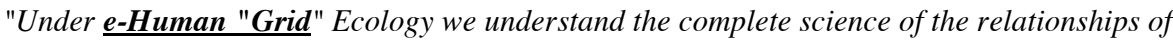
grid to the surrounding environment to which we can count all conditions of existence in the widest sense." [27]

(e-Human "Grid" Ecology" is)... the relationship between grid and all other e-Social sub-systems." [28] 


\section{Conclusions}

It is obvious that there are huge resources available in IT as in most other production and social sectors resulting in many opportunities. Similar phenomena are known for many sectors as e.g. the renewable energy sector. In contrast, ever more resources are said to be required but believed to be at their limit and thus already unavailable for further exploitation. Especially in IT the demand for information storage and processing in R\&D grows exponentially. Although exponential growth inevitably will lead to the reaching of limits sooner or later, there seems to be also many an opportunity to sustainably manage resources on very long time scales. Thus, clever resource management can increase the efficiency tremendously and in consequence avoid limiting barriers as e.g. integrated chemical production or sophisticated agro-forestry systems show. Grid infrastructures in IT are believed to be another of these solutions exploiting under-used and available resources. The IT sector and there especially the grid area with their fast technological turnover rates would, however, allow to bring innovation opportunities fast to the market and thereby increase the efficiency of computing and storage usage tremendously. This could result on the one hand in lower investments into infrastructure, which obviously would provoke large resistance by the producing industry, or on the other hand would result in a much higher output and thus return of investment made by society in these infrastructures, which would give a big "present" with only minor further investment to society as a whole. Nevertheless, it remains a big issue despite all the efforts of the grid and other communities, why the obvious huge benefits of much higher resource exploitation efficiencies is so hard to internalize into societies despite its crystal clear benefits.

The organizational architecture analysis of grid infrastructures and their management shows that there are four levels of stake-holders involved: i) users, ii) organizing broker organizations, iii) donor organizations, and iv) individual donors. That is a much more complicated situation compared to that of the integrated production in chemical industry, since here we have a large spatial and cultural coverage in contrast to the "internal" situation of one single company. There is also a big difference to sophisticated agro-forestry systems as e.g. those in Indonesia, since these systems had a huge temporal time span for development. Although they involve in principle the entire society, the decisions are still taken by the single farmer and community despite their a posteriori internalization in tradition and cultural rules. Abstraction of the four levels involved in grid infrastructures leads to a micro level from which a macro level emerges, having again an influence on the micro level and vice versa. The micro level is constituted by an invironment and the macro level creates an environment, which already constitutes the Human Ecology rectangle as we showed later. Consequently, here from the pure theoretical viewpoint we have not only reached complete consistency proving the validity of our arguments, but also gained access to a "tool box" used successfully for complex internalization issues. This is important for generalization and for justification thereof derived management measures.

The fact that IT resources are completely underused we identified additionally and for the first time as a phenomenon of the Inverse Tragedy of the Commons, i.e. that the resources are not overexploited unsustainably until their destruction. Together with the finding of the micro and macro level in the organization of grid organizations 
which plays the important role in both the Classic and Inverse Tragedy of the Commons leading to responsibility diffusion and thus inefficient resource management, consequently makes clear that the grid challenge concerning implementation and integration of grids lies in the social embedding of the micro and macro level phenomena: i) the sharing attitude/socialisation based on the security/risk/profit psychology of the individual, and ii) the culture of the embedding institution and society based on the interaction of the autopoietic social sub-systems. This is similar e.g. to the renewables sector and thus has huge implications beyond the grid sector.

Considering the macro level more in detail reveals that the autopoietic sub-systems theory describes the social environment best. Unfortunately, the social sub-systems i) religion, ii) education, iii) science, iv) art, v) economy, vi) jurisdiction, vii) policy, have a more or less incompatible code of communication which leads to the Tragedy of the Autopoietic Social Sub-Systems leading to large inconsistencies and blockings. Consequently, the grid challenge lies in the integration of autopoietic sub-systems towards a working grid society on the micro and macro level by i) approaching the sub-system stickyness of individuals, and ii) the soft bridging of sub-systems. In the daily work that means that the individuals have first to realize their own working and borders of their social sub-system as well as that of the other social sub-systems. In a second step the possible bridges between social sub-systems need to be realized and concrete ways to circumvent inherent blockings have to be explored to actually get to a working solution to reach the level of a joined effort to realize a project.

On the micro level the security/risk/profit psychology matrix plays the major role since for the individual each internalization of a new technology is based on a positive relation between the security/risk/profit involved. Even for clear win-win situations the phenomenon of responsibility diffusion can appear. Since individuals have to balance constantly between the invironment and the environment, i.e. between psychology and social sub-systems, there appears also a hard to tackle Tragedy of the Security/Risk/Profit Psychology. Consequently, the grid challenge on the micro and macro level are given by i) the individual perception and the individual well being, and ii) the procedural and institutionalized careful management. For the daily work that means that the individual need to rationalize its own behavioural background and invironmental constituency, and that institutions need to accept and develop the invironment of their employees as well as the psychological status of the environment they create. Thus, the creation of awareness might not change the individual but by team formation with different characters and corresponding procedures, the openness in an institutionalized form can increase the internalization of new technologies.

Consequently, to overcome the "dare-to-share" attitude in respect to the Inverse Tragedy of the Commons and its base tragedies, the Tragedy of Autopoietic Social Sub-Systems and the Tragedy of Security/Risk/Profit Psychology in the grid sector, a sustainable grid approach in an ecology-like manner combining the micro and macro level is crucial for the grid sector. The interdisciplinary field of Human Ecology gives a framework also for the understanding and approaching of the Classic and Inverse Tragedy of the Commons for direct guidelines in the day-to-day management of grids as well as other areas and combine the statements made above into a unified framework. Theoretically our analysis showed that it is necessary to extent the classical Human Ecology triangle to rectangle with i) the invironment ii) the individual, iii) the society, and iv) the environment. As mentioned before from the pure theoretical 
viewpoint, we have not only reached complete consistency proving the validity of our arguments, but also gained access to a "tool box" which has been used already successfully. This is important for generalization as well as for justification of thereof derived management measures. To rationalize that further on the theoretical level, this can be used to define the corresponding notion for $e$-Live and $e$-Society with $e$ Invironment as well as e-Environment extending the classic notion of ecology, which leads to e-Human Grid Ecology. Consequently, the Inverse Tragedy of the Grid Commons can be tackled on the micro and macro level: i) participative integration of the individual and acceptance of its invironment, and ii) sustainable integration of eSocial autopoietic sub-systems and its environment. Thus, we propose an ecological systems framework to deal with the phenomenon of under-used resources in the IT sector similar to the paradigms of integrated production in chemical industry and sophisticated agro-forestry systems e.g. in Indonesia.

In summary, we think that with the extended e-Human (Grid) Ecology rational, the Inverse Tragedy of the Commons of the grid and other sectors as e.g. the renewable energy field, cannot only be understood but also approached concerning the detailed daily work of implementation and internalization of new efficient strategies into society, which is of major importance for many fields where similar paradoxes appear and thus finally for the well-being of mankind and planet earth in general.

\section{Acknowledgements}

We are very thankful to the German and International Societies for Human Ecology and their members for discussion of the background of this work. We also would like to thank Nick Kepper, the Erasmus Computing Grid as well as the German MediGRID and Services@MediGRID consortia for their support. This work was partly supported by the Erasmus Medical Center and the Hogeschool Rotterdam, Rotterdam, The Netherlands, as well as the Bundesministerium für Bildung und Forschung (BMBF) under grant \# 01 AK 803 A-H (German MediGRID) and \# 01 IG 07015 G (German Services@ MediGRID) to TAK.

\section{References}

1. Faber, M., Manstetten, R.: Mensch - Natur - Wissen: Grundlagen der Umweltbildung. Vandenhoeck and Ruprecht, ISBN 3525301413, ISBN 978-3525301418, (2003)

2. Egger, K., Glaeser, B.: Ideologiekritik der Grünen Revolution: Wege zur technologischen Alternative, Technologie und Politik. rororo actuell, Reinbeck, (1975)

3. Faber, M., Niemes, H., Stephan, G., Freytag, L.: Entropy, Environment, and Resources. An Essay in Physico- Economics. Springer Verlag, ISBN 3540182489, ISBN 9783540182481, (1987)

4. IPCC: http://www.ipcc.ch and http://www.ipcc.ch/ipccreports/index.htm

5. Hardin, G.: Tragedy of the Commons. Science 162, 1243-1248, (1968)

6. Ostrom, E.: Governing the commons: The evolution of institutions for collective action. Cambridge University Press, ISBN 0521405998, ISBN 978-0521405997, (1990)

7. Hardin, G.: The Tragedy of the Unmanaged Commons. Trends in Ecology \& Evolution 9, 199, (1994).

8. Hardin, G.: Extensions of "The Tragedy of the Commons". Science 280, 682-683, (1998).

9. International Association for the Study of the Commons (IASC), http://www.iascp.org

10. Tragedy of the commons, http://en.wikipedia.org/wiki/Tragedy_of_the_commons

11. de Zeeuw, L.V., Knoch, T.A., van den Berg, J., Grosveld, F.G.: Erasmus Computing Grid - Het bouwen van een 20 TeraFLOP virtuelle supercomputer. In: Frederik, H. (ed.) NIOC 
proceedings 2007 - het perspective of lange termijn. NIOC, Amsterdam, The Netherlands, $52-59,(2007)$

12. Faber, M., Stephan, G., Michaelis, P.: Umdenken in der Abfallwirtschaft. Vermeiden, Verwerten, Beseitigen. Springer, ISBN 3540518398, ISBN 978-3540518396, (1989)

13. Jentzsch, W.I.: BASF Antwerp - an integrated chemical plant. Industrial Lubrication and Tribology 47, 4-5, (1995)

14. Faber, M., Schiller, J.: Joint Production and Responsibility in Ecological Economics: On the Foundations of Environmental Policy (Advances in Ecological Economics). Edward Elgar Publishing, ISBN 1840648724, ISBN 978-1840648720, (2006)

15. Egger, K., Rudolph, S.: Zum anschaulichen Umgang mit komplexen Aspekten der Kulturund Ökokrise. In: Glaeser, B., Teherani-Krönner, P. (eds.) Humanökologie und Kulturökologie - Grundlagen, Ansätze, Praxis. Westdeutscher Verlag, Opladen, 191-220, (1992)

16. Faber, M., Manstetten, R., Proops, J.: Ecological Economics: Concepts and Methods. Edward Elgar Publishing., ISBN-10: 1858989981, ISBN 978-1858989983, (1998)

17. Foster, I., Kesselman, C. The grid: blueprint for a new computing infrastructure. The Elsevier Series in Grid Computing. Morgan Kaufmann, Amsterdam and Boston, ISBN 1558609334, (2004)

18. Egger, K.: Die moralische Inversion - Ursachen unserer normativen Orientierungskrise und deren Folgen für die Agrarentwicklung - Alternativpositionen durch Dialog mit anderen Kulturen. In: Bruckmeier, K., Serbser, W.H. (eds.) Ethik und Umweltpolitik: Humanökologische Positionen und Perspektiven. Oekom Verlag, ISBN 978-3-86581-119-6, (2008)

19. Maturana, H.R., Varela, F.: Tree of Knowledge. Shambhala, ISBN 0877736421, ISBN 978-0877736424, (1992)

20. Luhmann, N.: Ökologische Kommunikation. VS Verlag für Sozialwissenschaften, ISBN 3531517759, ISBN 978-3531517759, (2004)

21. Luhmann, N.: Soziale Systeme: Grundriß einer allgemeinen Theorie. Suhrkamp, ISBN 3518282662, ISBN 978-3518282663, (2008)

22. Egger, K.: Evolution, Menschenbild und Umweltkrise - ein Versuch zur humanökologischen Hypothesenbildung. In: Wehrt, H. (ed.), Humanökologie - Beiträge zum ganzheitlichen Verständnis unserer geschichtlichen Lebenswelt. Birkhäuser, Basel, 155$189,(1996)$

23. Bruckmeier, K., Serbser, W.H. (eds.), Ethik und Umweltpolitik: Humanökologische Positionen und Perspektiven. Oekom Verlag, ISBN 978-3-86581-119-6, (2008)

24. Sax, U., Weisbecker, A., Falkner, J., Viezens, F., Yassene, M., Hartung, M., Bart, J., Krefting, D., Knoch, T.A., Semler, S.C.: Grid-basierte Services für die elektronische Patientenakte der Zukunft. E-HEALTH-COM - Magazin für Gesundheitstelematik und Telemedizin 4, 61-63, (2007)

25. Sax, U., Weisbecker, A., Falkner, J., Viezens, F., Mohammed, Y., Hartung, M., Bart, J., Krefting, D., Knoch, T.A., Semler, S.C.: Auf dem Weg zur individualisierten Medizin Grid-basierte Services für die EPA der Zukunft. In Jäckel, A. (ed.) J Telemedizinführer Deutschland 2008. Deutsches Medizinforum, Minerva KG, Darmstadt, ISBN 3-93794806-6, ISBN-13 9783937948065, 47-51, (2008)

26. Krefting, D., Bart, J., Beronov, K., Dzhimova, O., Falkner, J., Hartung, M., Hoheisel, A., Knoch, T.A., Lingner, T., Mohammed, U., Peter, K., Rahm, E., Sax, U., Sommerfeld, D., Steinke, T., Tolxdorff, T., Vossberg, M., Viezens, F., Weisbecker, A.: MediGRID - Towards a user friendly secured grid infrastructure. Future Generation Computer Systems 25, 326-336, (2008)

27. Haeckel, E.: Generelle Morphology der Organismen. Band 2 Allgemeine Entwicklungsgeschichte. Berlin, p. 286, (1866)

28. Haeckel, E.: Natürliche Schöpfungsgeschichte., 9. Auflage, Berlin, p. 793, (1898) 